\title{
ANÁLISE DE SUSTENTABILIDADE DOS BENEFICIADOS DO PROGRAMA CÉDULA DA TERRA NO MUNICÍPIO DE SOBRAL, ESTADO DO CEARÁ ${ }^{1}$
}

\author{
Thiago Dias Parente ${ }^{2}$ \\ Francisco José Silva Tabosa ${ }^{3}$ \\ Fernando Daniel de Oliveira Mayorga ${ }^{4}$ \\ Silvando Carmo de Oliveira ${ }^{5}$
}

Resumo: O objetivo deste estudo é analisar a sustentabilidade dos assentamentos beneficiados pelo Programa Cédula da Terra, no município de Sobral. Para este fim, elaborou-se um Índice de Sustentabilidade (IS) no qual foram consideradas diferentes variáveis representativas de desenvolvimento econômico-social, capital social e ambiental para os assentamentos. Foram determinantes os estudos desenvolvidos por Barreto, Khan e Lima (2005). Os resultados mostraram um alto nível de Sustentabilidade para o Assentamento Macapá e um nível médio de Sustentabilidade para os Assentamentos São João e Picada.

Palavras-chave: Desenvolvimento Sustentável; Programa Cédula da Terra; Sobral.

Abstract: The objective of this study is examining the sustainability of settlements of the Cedula da Terra Program, in the municipality of Sobral. For this, was prepared an index of Sustainability (IS) whereas different variables representing economic and social development, social capital and environmental settlements. It is based on studies undertaken by Barreto, Khan and Lima (2005). The results showed an high level of Sustainability for Macapa and average level of Sustainability for the São João and Picada.

Key Words: Sustainable Development; Cédula da Terra Program; Sobral.

Recebido em: 17/11/2010. Aceito em: 11/04/11.

Bacharel em Economia pela Universidade Federal do Ceará - Campus Sobral. E-mail: txiagu@ hotmail.com.

Economista. Professor Adjunto I do Curso de Ciências Econômicas na Universidade Federal do Ceará Campus Sobral. Doutor em Economia pelo CAEN/UFC. Pesquisador do Laboratório de Estudos Regionais (LER). E-mail: franzetabosa@ufc.br.

4 Economista. Phd Candidate na Universidade do Arizona (USA). Professor Assistente I do Curso de Ciências Econômicas na Universidade Federal do Ceará - Campus Sobral. E-mail: fmayorga@ufc.br.

5 Economista. Professor Assistente II do Curso de Ciências Econômicas na Universidade Federal do Ceará Campus Sobral. E-mail: scaoli@oi.com.br. 


\section{Introdução}

Embora seja um dos mais pobres estados da Federação, o Estado do Ceará tem se destacado por suas altas taxas acumuladas de crescimento econômico. Basta observar os números: no período de 1985 a 1999, a taxa acumulada de variação do PIB cearense registrou a marca dos $61,53 \%$ comparativamente maior que as taxas do Nordeste e do PIB nacional, de 40,64\% e 49,5\%, respectivamente (MAIA apud TABOSA et al., 2010). Apesar desse quadro animador e auspicioso, ele é monolítico, pois o estado reincide em apresentar, por outro lado, indicadores sociais inconvenientes.

O Índice de Desenvolvimento Humano (IDH) do Estado do Ceará era de 0,593, acima somente de quatro estados do Nordeste (Bahia, Maranhão, Paraíba e Piauí). Proporcionalmente, a quantidade de pobres, em 1995, correspondia a $64,31 \%$ da população, abaixo da linha de pobreza de $1 / 2$ salário-mínimo. $\mathrm{Na}$ área rural, a pobreza representava $84,63 \%$ de sua população. Já em relação à desigualdade de renda, em 1995, o Ceará apresentou um Índice de Gini igual a 0,617, abaixo somente do Estado de Alagoas, detentor de um índice de 0,644 (BARRETO, GASPAR e ARAÚJO, 2009).

Por mais que o crescimento econômico do Estado do Ceará tenha alcançado taxas bem elevadas em comparação tanto aos outros estados do Nordeste quanto em âmbito nacional, os níveis de pobreza e as desigualdades de renda são elevados (BAR-EL, 2002). E uma das principais razões dessas disparidades é que a maior parte da população interiorana ainda depende do emprego agrícola. Sendo os mais pobres, não os trabalhadores que moram nas fazendas, e sim, os minifundiários.

Comprometido a reduzir essa desigualdade no setor rural, pela promoção do desenvolvimento social e econômico desse setor, o governo do Estado do Ceará reformulou, no ano de 1995, o Programa de Apoio ao Pequeno Produtor (PAPP), cuja origem é datada dos anos de 1985, e que mais tarde seria batizado de Projeto São José (PSJ). Esse projeto teve o objetivo 
de incentivar as práticas de desenvolvimento sustentável das comunidades beneficiadas, no intuito de aumentar sua participação no mercado e, consequentemente, sua renda, promovendo uma melhoria no setor de infraestrutura e emprego da região, para reduzir a pobreza rural.

Em 1996, o Projeto São José (PSJ) passa a ser denominado Programa de Combate à Pobreza Rural (PCPR). Segundo Khan e Silva (2005, p. 102): "[...] neste sentido, foram financiados e implantados, no período de 1996 a 1998, vários subprojetos relacionados à infraestrutura, produção e desenvolvimento social em comunidades distribuídas em municípios situados em diferentes microrregiões do Estado do Ceará." A implementação do PCPR contribuiu para avanços significativos no capital social intangível e tangível das associações e/ou comunidades, sendo constatado que todos os indicadores de capital social tangível das comunidades pesquisadas melhoraram, em maior ou menor escala, depois da implantação do PCPR (KHAN e SILVA, 2005).

Com o sucesso do Fundo Rotativo da Terra (FRT), um dos segmentos do PCPR em parceria com o Banco Mundial, surgiu o projeto piloto chamado de Reforma Agrária Solidária no ano de 1996, destinado a financiar imóveis em áreas rurais para trabalhadores minifundiários e trabalhadores sem terra. Foram criados, posteriormente, programas em nível federal, como Cédula da Terra, Banco da Terra e PCPR/Crédito Fundiário.

O Programa Cédula da Terra (PCT) foi implementado em caráter piloto no período 1997-2003 em cinco estados da federação (Bahia, Ceará, Maranhão, Minas Gerais e Pernambuco). Esse programa foi expandido ao resto do país, agora com o nome de Programa Banco da Terra. Tinha por objetivo central reduzir a pobreza rural nas regiões mais deprimidas do País e desenvolver novo modelo de reestruturação agrária no qual os trabalhadores sem-terra e minifundiários negociariam a aquisição de terras diretamente com os proprietários rurais. Em quase sua totalidade, o público-alvo era composto por trabalhadores rurais sem-terra (assalariados, parceiros, pequenos arrendatários, trabalhadores que possuem pouca terra - minifundiários). Bastava ser chefe de família, ter tradição na atividade agropecuária e ser maior de idade ou emancipado. 
O PCT constatou os efeitos preliminares positivos do Programa sobre as condições de vida da população de beneficiários, notadamente no que se refere à renda, condições de habitação, acesso aos serviços públicos, nível de organização e patrimônio doméstico (UNICAMP, 2002). Em relação aos produtores do Programa Cédula da Terra, o nível tecnológico apresentado ainda é muito baixo e enfrentam restrições de crédito para realizar os investimentos necessários para mudar qualitativamente a estrutura produtiva (SOUZA FILHO et al., 2003).

O Programa Cédula da Terra atuou em quase todos os municípios do Estado do Ceará, inclusive no município de Sobral cujo PIB em 2007 era de R \$ 1.752.648 mil, representando 3,48\% do PIB do Estado do Ceará, com o setor agropecuário participando com 1,8\% do total municipal e $6,2 \%$ do total estadual. Em 2008, Sobral alcançava o $3^{\circ}$ lugar no ranking do IDM (Índice de Desenvolvimento Municipal) do estado (IPECE, 2010).

O município de Sobral foi um dos municípios mais beneficiados pelo Programa Cédula da Terra, uma vez que ele tem quatro assentamentos atendidos pelo Programa Cédula da Terra: Macapá, São João, Picada e Alegre. Todavia, não existem estudos analisando as condições socioeconômicas e a sustentabilidade dessas famílias assentadas.

Assim, o objetivo deste estudo é analisar a sustentabilidade dos assentamentos beneficiados pelo Programa Cédula da Terra, no município de Sobral, considerando aspectos econômico-sociais, ambientais e a mobilização do capital social dentro do projeto, com o intuito de contribuir para diagnosticar possíveis entraves que possam ser superados para a promoção do desenvolvimento rural sustentável. 


\section{Metodologia}

\subsection{Procedimento Metodológico}

Neste trabalho, foi elaborado um Índice de Sustentabilidade (IS) considerando diferentes variáveis representativas do desenvolvimento econômico-social, capital social e ambiental para os assentamentos, baseado nos estudos desenvolvidos por Barreto, Khan e Lima (2005).

Para a elaboração do Índice de Sustentabilidade, foi necessária a elaboração de outros três índices - desenvolvimento econômico-social, capital social e ambiental - que serão definidos a seguir.

\subsection{1. Índice de Desenvolvimento Econômico-Social - IDES}

Para verificar se os assentamentos têm contribuído para a melhoria da qualidade de vida de seus beneficiários, realizou-se uma avaliação a partir de um índice resultante da agregação de indicadores como educação, saúde, habitação, aspectos sanitários, indicador de informação, lazer e renda.

O método utilizado foi desenvolvido por Fernandes apud Khan (2001) e apresenta os seguintes passos: I) estabelecimento dos indicadores que constituem o Índice de Desenvolvimento Econômico-Social (IDES) com seus respectivos escores; II) organização de postos posicionados em ordem crescente de valores, partindo da situação em que o indicador é menos expressivo, até a situação em que poderia atingir seu melhor desempenho.

Quanto aos escores, eles assumiram valores de 0 a 4 para expressar a opinião dos produtores assentados na escala ascendente de posto.

Assim, matematicamente, pode-se definir o IDES como: 


$$
I D E S=\frac{1}{n} \sum_{j=1}^{n}\left(\frac{\sum_{i=1}^{m} E i j}{\sum_{i=1}^{m} E \operatorname{maxi}}\right)
$$

A contribuição de cada indicador no IDES das comunidades foi obtida da seguinte maneira:

$$
C i=\frac{\sum_{i=1}^{m} E i j}{n\left(\sum_{i=1}^{m} E \max i\right)}
$$

Sendo IDES, o Índice de Desenvolvimento Econômico-Social; Eij, o escore do i-ésimo indicador obtido pela j-ésimo produtor; Emax, i, o escore máximo do i-ésimo indicador; $\mathrm{Ci}$, a contribuição do indicador "i" no índice de desenvolvimento econômico-social dos assentados; $\mathrm{i}=1, \ldots$, $\mathrm{m}$, número de indicadores; $\mathrm{e} \mathrm{j}=1, \ldots, \mathrm{n}$, número de assentados.

Abaixo, segue a relação dos indicadores utilizados no modelo com seus respectivos escores, para a aferição do Índice de Desenvolvimento Econômico-Social - IDES.

\section{SAÚDE}

\section{I - Disponibilidade de serviços de saúde para comunidade}
A) Ausência de serviços de saúde. .0
B) Atendimento de primeiros socorros. .1
C) Atendimento por agente de saúde. .2
D) Atendimento médico. 3 

A) Ausência de serviços de saúde .0
B) Atendimento de primeiros socorros 1
C) Atendimento por agente de saúde.................................................2
D) Atendimento médico......................................................................

\section{III - Na sua comunidade existe}
A) Nenhuma das opções.
B) Posto de Saúde .1
C) Hospital.

\section{EDUCAÇÃO}

\section{I - Disponibilidade de serviços educacionais no assentamento}
A) Ausência de escolas públicas ou comunitárias .0
B) Escolas de cursos de alfabetização................................................1

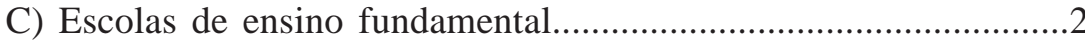

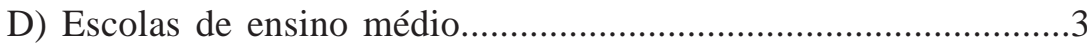

II - Disponibilidade de serviços educacionais para sua família
A) Ausência de escolas públicas ou comunitárias .0
B) Escolas de cursos de alfabetização...............................................1

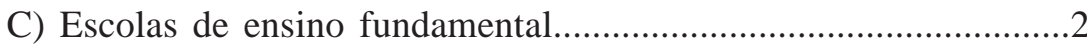

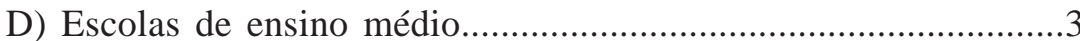




\section{HABITAÇÃO}

I - Tipo de construção da sua residência
A) casa de taipa .1
B) casa de tijolo, sem reboco e piso. 2
C) casa de tijolo, com reboco e piso 3

II - A principal fonte de iluminação da sua residência é
A) Lampião a querosene ou a gás ou lamparina e/ou velas . .1

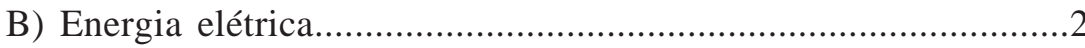

\section{CONDIÇÕES SANITÁRIAS E HIGIENE}

\section{I - Destino dado aos dejetos humanos}
A) Jogado a céu aberto ou enterrado .1
B) Dirigido à fossa ou rede de esgoto. .2

\section{II - Tratamento dado à água para consumo humano}
A) Nenhum tratamento
B) Fervida, filtrada ou com hipoclorito de sódio. . .1

\section{III - Destino dado ao lixo domiciliar}
A) Jogado ao solo ou queimado . .1
B) Enterrado ou recolhido através de coleta domiciliar. .2 


\section{ECONÔMICO}

\section{I - Sua família possui renda mensal...}
A) Menor do que 1 salário-mínimo .1
B) Entre 1 e 3 salários-mínimos.........................................................2
C) Maior do que 3 salários-mínimos......................................................

\section{INFORMAÇÃO}

\section{I - Distância entre sua residência e a sede do município}
A) Menos de 15 minutos
.4

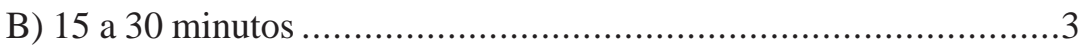

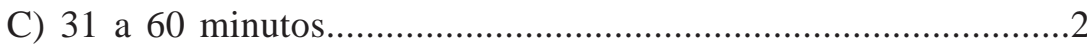

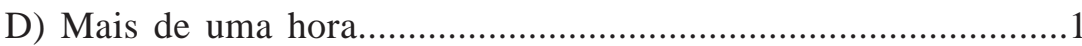

\section{II - Parte do ano a sua casa é acessível pela estrada}
A) Durante o ano todo. 3
B) Apenas durante algumas estações..............................................2
C) Nunca é facilmente acessível....................................................... 
Quanto mais próximo de 1, maior o valor do Índice de Desenvolvimento Econômico-Social, IDES, nas comunidades. Optou-se por estabelecer o seguinte critério:
a)Baixo nível do Índice de Desenvolvimento Econômico - Social $0<\operatorname{IDES} \leq 0,5$
b)Médio nível do Índice de Desenvolvimento Econômico - Social 0,5 < IDES $\leq$ 0,8
c)Alto nível do Índice de Desenvolvimento Econômico - Social 0,8 $<$ IDES $\leq 1,0$

\subsection{2. Índice de Capital Social - ICS}

O capital social neste estudo foi elaborado a partir dos indicadores que expressam as relações interpessoais entre os membros beneficiados pelo Programa de Reforma Agrária e sua participação em associações de caráter participativo, cooperativo e, consequentemente, canalizador de recursos destinados à promoção do desenvolvimento dos assentados $\mathrm{e}$ de suas famílias. A acumulação do capital social intangível dos assentados selecionados será avaliada pelo do Îndice de Capital Social (ICS).

Assim, matematicamente, pode-se definir o ICS como:

$$
I C S=\frac{1}{n} \sum_{j=1}^{n}\left(\frac{\sum_{i=1}^{m} E i j}{\sum_{i=1}^{m} E \operatorname{maxi}}\right)
$$

A contribuição de cada variável no ICS das comunidades foi obtida da seguinte maneira:

$$
C i=\frac{\sum_{j=1}^{n} E i j}{n \sum_{j=1}^{n} E \operatorname{maxi}}
$$


Thiago Dias Parente, Francisco José Silva Tabosa,

Fernando Daniel de Oliveira Mayorga \& Silvando Carmo de Oliveira

Sendo ICS, o Índice de capital social; $\mathrm{E}_{\mathrm{ij}}$, e escore do $i$-ésimo indicador obtido pelo j-ésimo assentado; $\mathrm{E}_{\max , \mathrm{i}}$, o escore máximo da $i$-ésimo indicador; $\mathrm{C}_{\mathrm{i}}$, a contribuição do indicador " $i$ " no índice de Capital Social; $\mathrm{i}=1, \ldots ., \mathrm{m}$, número de indicadores; $\mathrm{e} \mathrm{j}=1, \ldots ., \mathrm{n}$, número de assentados.

Abaixo segue a relação dos indicadores utilizados no modelo com seus respectivos escores, para a aferição do Índice de Capital Social - ICS.

I) Interesse pelo seu bem-estar e não preocupação com o bem-estar da comunidade.

(0) $\mathrm{Sim}$

(1) Não

II) Frequenta as reuniões da associação.

(1) $\operatorname{Sim}$

(0) Não

III) Comunicado e convidado para assistir a reuniões da associação.

(1) $\mathrm{Sim}$

(0) Não

IV) Participa da escolha dos líderes da associação. (1) Sim

(0) Não

V) As decisões são aprovadas em reuniões/assembleias.

(1) Sim (0) Não

VI) Apresenta sugestões nas reuniões.

(1) $\operatorname{Sim}$

(0) Não

VII) As decisões tomadas são efetivamente executadas pela diretoria. (1) Sim (0) Não

VIII) Os dirigentes fazem a prestação de contas com os associados. (1) $\operatorname{Sim} \quad$ (0) Não

IX) Paga taxa mensal.

(1) $\operatorname{Sim}$

(0) Não

X) Participa na elaboração de eventos sociais.

(1) $\mathrm{Sim}$

(0) Não 
XI) Se tiver um problema, sempre aparecerá alguém para ajudar.

(1) Sim

(0) Não

XII) Desempenhou algum cargo ou teve algum tipo de responsabilidade no funcionamento de alguma entidade, associação da sua região ou da sua cidade.
(1) Sim
(0) Não

Quanto mais próximo de 1, maior o valor do Índice de Capital Social, ICS, nas comunidades. Optou-se por estabelecer o seguinte critério:
a)Baixo nível do Índice de Capital Social
$0<\mathrm{ICS} \leq 0,5$
b)Médio nível do Índice de Capital Social
$0,5<\mathrm{ICS} \leq 0,8$
c)Alto nível do Índice de Capital Social
$0,8<\mathrm{ICS} \leq 1,0$

\subsection{3. Índice Ambiental - IA}

O índice ambiental foi calculado pelas respostas às perguntas básicas referentes às comunidades. Uma justificativa para o índice de sustentabilidade ambiental seria a seguinte: a pergunta referente à preservação ou à recuperação do solo é uma questão básica, ou seja, qualquer atividade agrícola que destrua o solo, seja a curto ou em longo prazo, não pode de forma alguma ser considerada uma atividade que esteja de acordo com o conceito e a prática de desenvolvimento sustentável.

A biodiversidade é outra questão importante, pois sua redução gera implicações bastante sérias sobre o equilíbrio ambiental. Em caso extremo, tem-se a monocultura, que está mais exposta ao ataque de pragas, devido a uma redução da biodiversidade e, por isso, se torna mais dependente de agrotóxicos. Portanto, este aspecto representa um fator negativo em termos de sustentabilidade ambiental. 
Assim, matematicamente, pode-se definir o IA como:

$$
I A=\frac{1}{n} \sum_{j=1}^{n}\left(\frac{1}{m} \sum_{i=1}^{m}\left(E i j / E_{\max i}\right)\right)
$$

A contribuição de cada variável no IA das comunidades foi obtida da seguinte maneira:

$$
C i=\frac{\sum_{j=1}^{n} E i j}{n \sum_{j=1}^{n} E \operatorname{maxi}}
$$

Tal que IA é o Índice Ambiental; $\mathrm{E}_{\mathrm{ij}}$, o escore da $i$-ésimo indicador obtida pela j-ésimo associado; $\mathrm{E}_{\max , \mathrm{i}}$, o escore máximo da $i$-ésimo indicador; $\mathrm{C}_{\mathrm{i}}$ , a contribuição do indicador " $i$ " no índice Ambiental; $i=1, \ldots ., \mathrm{m}$, número de indicadores; $\mathrm{e} \mathrm{j}=1, \ldots, \mathrm{n}$, número de assentados.

Abaixo segue a relação dos indicadores utilizados no modelo com seus respectivos escores, para a aferição do Índice Ambiental - IA.

I) Método de controle de pragas utilizado na unidade produtiva.
(0) Agrotóxico
(1) Nenhum
(2) Biológico

II) Utilização de fogo nas atividades agropecuárias.
(0) Sim
(1) Não

III) Plantio de árvores para fins de conservação de solos.

(0) Não (1) Sim

IV) Existência de área de reserva de mata nativa na propriedade.
(0) Não
(1) $\operatorname{Sim}$ 
V) Uso de prática de plantio para evitar a degradação do solo.

(0) Não (1) Sim

VI) Casa com sistema de esgoto ou algum tipo de fossa.

(0) Não (1) Sim

VII) Utilização de rotação de cultura.

(0) Não (1) Sim

VIII) Se necessário, faz calagem.

(0) Não (1) Sim

IX) Utilização de esterco animal.

(0) Não (1) Sim

X) Utilização do solo de acordo com a sua vocação. (0) Não (1) Sim

Quanto mais próximo de 1, maior o valor do Índice ambiental, IA, nas comunidades. Optou-se por estabelecer o seguinte critério:
a)Baixo nível do Índice Ambiental $\quad 0<\mathrm{IA} \leq 0,5$
b)Médio nível do Índice Ambiental $\quad 0,5<\mathrm{IA} \leq 0,8$
c)Alto nível do Índice Ambiental $\quad 0,8<\mathrm{IA} \leq 1,0$

\subsection{4. Índice de Sustentabilidade - IS}

Os indicadores utilizados para medir a sustentabilidade no presente trabalho estão divididos em três: Indicador de Desenvolvimento Econômico-Social, Indicador Ambiental e Indicador de Capital Social.

Dentro desta visão, foi desenvolvido o seguinte Índice de Sustentabilidade (IS): 
$I S=\frac{1}{k} \sum_{h=1}^{k} I h$

Tal que IS é o Índice de Sustentabilidade; I, o valor do $h$-ésimo índice; e h, o IDES, ICS e IA.

O valor do Índice de Sustentabilidade é a média aritmética dos três índices citados anteriormente, e quanto mais próximo de 1 , maior o indicador de sustentabilidade nas comunidades. O indicador está dentro do intervalo: $0<I S \leq 1$

Optou-se por estabelecer o seguinte critério, de acordo com Barreto, Khan e Lima (2005):

a)Baixo nível de Sustentabilidade

$0<I S \leq 0,5$

b)Médio nível de Sustentabilidade

$0,5<I S \leq 0,8$

c)Alto nível de Sustentabilidade

$0,8<I S \leq 1,0$

\subsection{Base de Dados e Área de Estudo}

Os dados utilizados neste estudo são de origem primária, obtidos pela aplicação de questionários junto às famílias beneficiadas em cada assentamento do Programa Cédula da Terra. A pesquisa foi realizada nos assentamentos de reforma agrária, no município de Sobral, Estado do Ceará, no ano de 2010.

De acordo com a Empresa de Assistência Técnica e Extensão Rural do Ceará (Ematerce), os assentamentos são: Macapá, distante cerca de 66 km da sede do município, com dez famílias; São João, distante cerca de 80 km da sede do município, com dez famílias; Picada, distante cerca de $60 \mathrm{~km}$ da sede do município, com seis famílias; e Alegre, distante cerca de $24 \mathrm{~km}$ da sede do município, com oito famílias. Foram aplicados 26 questionários em três assentamentos. No assentamento Alegre, não foi 
possível a aplicação dos questionários por recomendações do Sindicato dos Trabalhadores Rurais de Sobral e também por técnicos da EMATERCE devido a conflitos internos dentro do assentamento, não sendo segura a visita para o estudo no assentamento.

\section{Resultados}

Agora serão apresentados os resultados sobre o Índice de Desenvolvimento Econômico-Social, Índices de Capital Social, Índice Ambiental e o Índice de Sustentabilidade nos Assentamentos São João, Macapá e Picada, município de Sobral, Estado do Ceará.

\section{1. Índice de Desenvolvimento Econômico-Social dos assentados nos Assentamentos São João, Macapá e Picada}

A Tabela 1 apresenta os resultados do Índice de Desenvolvimento Econômico-Social e a respectiva contribuição de cada indicador.

Tabela 1 - Contribuição dos Indicadores na Composição do Índice de Desenvolvimento Econômico-Social (IDES) nos Assentamento São João, Macapá, Picada e Amostra Total, 2010.

\begin{tabular}{|c|c|c|c|c|c|c|c|c|}
\hline \multicolumn{10}{|c|}{ Assentamentos } \\
\hline & $\begin{array}{c}\text { São João } \\
\text { INDICADOR }\end{array}$ & \multicolumn{2}{c|}{ Macapá } & \multicolumn{2}{c|}{ Picada } & \multicolumn{2}{c|}{ Amostra Total } \\
\cline { 2 - 10 } & os & $\begin{array}{c}\text { Val. } \\
\text { Relativ } \\
\text { os }\end{array}$ & $\begin{array}{c}\text { Val. } \\
\text { Absolut } \\
\text { os }\end{array}$ & $\begin{array}{c}\text { Val. } \\
\text { Relativ } \\
\text { os }\end{array}$ & $\begin{array}{c}\text { Val. } \\
\text { Absolut } \\
\text { os }\end{array}$ & $\begin{array}{c}\text { Val. } \\
\text { Relativ } \\
\text { os }\end{array}$ & $\begin{array}{c}\text { Val. } \\
\text { Absolut } \\
\text { os }\end{array}$ & $\begin{array}{c}\text { Val. } \\
\text { Relativ } \\
\text { os }\end{array}$ \\
\hline Saúde & 0.083 & 14,90 & 0.104 & 14,70 & 0.062 & 13,30 & 0.083 & 14,40 \\
\hline Educação & 0.077 & 13,90 & 0.101 & 14,30 & 0.111 & 23,70 & 0.096 & 16,70 \\
\hline Habitação & 0.167 & 29,90 & 0.167 & 23,50 & 0.144 & 30,90 & 0.015 & 27,60 \\
\hline $\begin{array}{c}\text { Condições } \\
\text { Sanitárias e } \\
\text { Higiene }\end{array}$ & 0.056 & 09,90 & 0.111 & 15,70 & 0.000 & 00,00 & 0.055 & 09,60 \\
\hline Econômico & 0.077 & 13,96 & 0.104 & 14,80 & 0.077 & 16,60 & 0.086 & 15,00 \\
\hline Informação & 0.095 & 17,10 & 0.119 & 16,80 & 0.071 & 15,30 & 0.095 & 16,50 \\
\hline IDES & $\mathbf{0 . 5 5 6}$ & $\mathbf{1 0 0 , 0 0}$ & $\mathbf{0 . 7 0 7}$ & $\mathbf{1 0 0 , 0 0}$ & $\mathbf{0 . 4 6 7}$ & $\mathbf{1 0 0 , 0 0}$ & $\mathbf{0 . 5 7 7}$ & $\mathbf{1 0 0 , 0 0}$ \\
\hline
\end{tabular}

Fonte: Dados de Pesquisa. 
Thiago Dias Parente, Francisco José Silva Tabosa,

Fernando Daniel de Oliveira Mayorga \& Silvando Carmo de Oliveira

Na composição da Tabela 1, o Indicador Saúde apresentou uma participação na composição do Índice de Desenvolvimento EconômicoSocial (IDES) entre 13,3\% a 14,9\% nos três assentamentos. Já o Indicador Educação apresentou uma diferença em cada assentamento. Para Picada, o Indicador Educacional tem uma participação de 23,70\% do IDES, enquanto para São João e Picada, uma participação de 13,90\% e $14,30 \%$ do IDES, respectivamente

O Indicador Habitação tem a melhor participação nos três assentamentos em cada um dos seus IDES. São João e Picada, com uma participação em torno de 30\% do IDES, e Macapá, com 23,50\% do IDES.

Para as Condições Sanitárias e Higiene, as piores participações para a composição do IDES foram: o assentamento Macapá, com 15,70\%; São João, com 9,90\%; e Picada, com 0,00\%. Para o Indicador Econômico, os valores variam entre $13,96 \%$ a $16,60 \%$ na composição do IDES. E por último, o Indicador Informação, que tem uma variação de contribuição entre 15,30\% (Picada) a 17,10\% (São João) na composição do IDES.

Para a Amostra Total, o Indicador Habitacional apresenta a maior contribuição, com 27,60\% do Índice de Desenvolvimento EconômicoSocial (IDES), seguido do Indicador Educacional, com 16,70\%. Para análise do IDES, o Assentamento São João apresentou um nível médio de Desenvolvimento Econômico-Social, com um valor de 0.556, enquanto Macapá apresentou um valor de 0.707 de IDES, possuindo também um nível médio. Já Picada apresentou um baixo nível de Desenvolvimento Econômico-Social, com 0,467. Para a Amostra Total, temos um nível médio de Desenvolvimento Econômico-Social da ordem de 0,577.

O Assentamento Macapá apresenta um maior Índice de Desenvolvimento Econômico-Social em virtude de melhores condições de habitação, sanitárias e higiene, econômicas, informação e saúde do que os Assentamentos São João e Picada. Foram observadas também precárias condições sanitárias e de higiene no assentamento Picada. 


\section{2. Índices de Capital Social nos Assentamentos São João, Macapá e Picada}

Na composição do Índice de Capital Social (ICS), o assentamento São João apresentou um Índice de Capital Social no valor de 0.891, enquanto nos assentamentos Macapá e Picada, este índice foi de 0.870 e 0.767 , respectivamente. Os assentamentos São João e Macapá apresentaram um alto nível do ICS, todavia, o assentamento Picada, apesar de ter atingindo um nível médio de ICS, chegou muito próximo de um nível alto.

\section{3. Índices de Ambiental nos Assentamentos São João, Macapá e Picada}

Na composição do Índice Ambiental, o assentamento São João apresentou um índice Ambiental com valor de 0.600, enquanto Macapá apresentou um índice de 0.878 e Picada obteve 0.345. Foi observada uma grande diferença entre os índices Ambientais de São João e Macapá em relação ao índice de Picada. Um dos motivos está no fato de os assentados de Picada não possuírem uma educação ambiental adequada, ainda fazendo uso de métodos como queimadas, não rotação de cultura e fraco controle contra pragas. Em todos os assentamentos, estão sendo preservadas as áreas de reserva de mata nativa. 
Thiago Dias Parente, Francisco José Silva Tabosa,

Fernando Daniel de Oliveira Mayorga \& Silvando Carmo de Oliveira

3.4. Índices de Sustentabilidade nos Assentamentos São João, Macapá e Picada

A Tabela 2 apresenta as contribuições dos indicadores na composição do Índice de Sustentabilidade nos assentamentos São João, Macapá e Picada.

Tabela 2 - Contribuição dos indicadores na Composição do Índice de Sustentabilidade nos Assentamento São João, Macapá, Picada e Amostra Total, 2010.

\begin{tabular}{|c|c|c|c|c|c|c|c|c|}
\hline \multicolumn{9}{|c|}{ Assentamentos } \\
\hline \multirow{2}{*}{ INDICADOR } & \multicolumn{2}{|c|}{ São João } & \multicolumn{2}{c|}{ Macapá } & \multicolumn{2}{c|}{ Picada } & \multicolumn{2}{c|}{ Amostra Total } \\
\cline { 2 - 9 } & $\begin{array}{c}\text { Val. } \\
\text { Absolutos }\end{array}$ & $\begin{array}{c}\text { Val. } \\
\text { Relativos }\end{array}$ & $\begin{array}{c}\text { Val. } \\
\text { Absolutos }\end{array}$ & $\begin{array}{c}\text { Val. } \\
\text { Relativos }\end{array}$ & $\begin{array}{c}\text { Val. } \\
\text { Absolutos }\end{array}$ & $\begin{array}{c}\text { Val. } \\
\text { Relativos }\end{array}$ & $\begin{array}{c}\text { Val. } \\
\text { Absolutos }\end{array}$ & $\begin{array}{c}\text { Val. } \\
\text { Relativos }\end{array}$ \\
\hline $\begin{array}{c}\text { Desenvolv. } \\
\text { Econômico-Social }\end{array}$ & 0.185 & 27.16 & 0.235 & 28.80 & 0.155 & 29.59 & 0.192 & 28.45 \\
\hline Capital Social & 0.297 & 43.54 & 0.290 & 35.43 & 0.255 & 48.54 & 0.280 & 41.56 \\
\hline Ambiental & 0.200 & 29.30 & 0.293 & 35.77 & 0.116 & 21.87 & 0.202 & 29.99 \\
\hline Sustentabilidade & $\mathbf{0 . 6 8 2}$ & $\mathbf{1 0 0 , 0 0}$ & $\mathbf{0 . 8 1 8}$ & $\mathbf{1 0 0 , 0 0}$ & $\mathbf{0 . 5 2 6}$ & $\mathbf{1 0 0 , 0 0}$ & $\mathbf{0 . 6 7 6}$ & $\mathbf{1 0 0 , 0 0}$ \\
\hline
\end{tabular}

Fonte: Dados de Pesquisa

Como vimos na Tabela 2, o Índice de Sustentabilidade (IS) dos assentamentos foi da ordem de $0.682,0.818$ e 0,526 para os assentamentos São João, Macapá e Picada, respectivamente. Os resultados mostraram um nível médio de Sustentabilidade para os assentamentos São João e Picada e um alto nível de Sustentabilidade para o Macapá.

Para o assentamento São João, o Índice de Desenvolvimento EconômicoSocial (IDES) contribuiu com $27.16 \%$ para a formação do Índice de Sustentabilidade, enquanto o Índice de Capital Social (ICS) contribuiu com 43.54\% e o Índice Ambiental (IA), com 29,30\%. O índice de maior contribuição foi o ICS e o de menor, o IDES.

No assentamento Macapá, o Índice de Desenvolvimento EconômicoSocial contribuiu com $28.80 \%$ para a formação do Índice de Sustentabilidade, enquanto o Índice de Capital Social contribuiu com $35.43 \%$ e o Índice Ambiental, com $35.77 \%$. O índice de maior contribuição foi o IA e o de menor, o IDES. 
Finalmente, no assentamento Picada, o Índice de Desenvolvimento Econômico-Social contribuiu em $29.59 \%$ para a formação do Índice de Sustentabilidade, enquanto o Índice de Capital Social, com $8.54 \%$, e o Índice Ambiental, com 21.87\%. O índice de maior contribuição foi o ICS, com quase $50 \%$, e o de menor, o IA.

Em resumo, o assentamento Macapá apresentou um alto nível de Sustentabilidade em decorrência dos elevados índices de Desenvolvimento Econômico-Social (IDES), de Capital Social (ICS) e Ambiental (IA). No entanto, os baixos índices de Desenvolvimento Econômico-Social (IDES) e Ambiental (IA) do Assentamento Picada são preocupantes, principalmente pelas condições sanitárias e de higiene existentes na comunidade, além dos problemas de educação ambiental.

\section{Conclusão}

A primeira conclusão é que o Indicador de Desenvolvimento EconômicoSocial (IDES) apresenta a menor contribuição para o Índice de Sustentabilidade (IS) nos assentamentos do Programa Cédula da Terra (PCT) e na Amostra Total, com exceção do assentamento Picada. Na amostra total, por exemplo, este indicador contribuiu com apenas $28,45 \%$ para o Índice de Sustentabilidade (IS), enquanto o Índice de Capital Social (ICS) contribuiu com 41,56\%.

No Índice de Desenvolvimento Econômico-Social (IDES), destaca-se positivamente o Indicador Habitacional, com quase todas as casas com tijolos, rebocos e pisos, e todas possuindo energia elétrica. Porém como fator negativo, as condições de higiene e sanitárias dos assentados são baixas, sem fossa ou redes de esgotos, água tratada para consumo humano e local para guardar os lixos. Este resultado se torna pior e preocupante no assentamento Picada.

Outro destaque positivo é o elevado Índice de Capital Social dos Assentamentos, como um fator preponderante no desenvolvimento existente nos assentamentos, já que os dois assentamentos, São João e 
Thiago Dias Parente, Francisco José Silva Tabosa,

Fernando Daniel de Oliveira Mayorga \& Silvando Carmo de Oliveira

Macapá, com o Índice de Capital Social (ICS) acima de 0.8, apresentaram um Índice de Sustentabilidade (IS) de 0,682 e 0,818, respectivamente, superior ao do Assentamento Picada, de 0,676, que apresentou um Índice de Capital Social igual a 0,767. Isto comprova que quanto maiores os níveis de capital social maiores são as condições de sustentabilidade das comunidades, conforme o resultado obtido por Barreto, Khan e Lima (2005).

Os assentados de São João e Macapá possuem um comprometimento em participações de reuniões da associação, apresentam sugestões e tomam decisões nas assembleias, escolha dos líderes através de votações e participam nas realizações de eventos, não deixando para o líder todo o trabalho.

Outro ponto que chamou atenção foi a distância nas contribuições do Índice Ambiental (IA) para o Índice de Sustentabilidade (IS) nos assentamentos Macapá e Picada. No assentamento Macapá, esta contribuição foi de $35,77 \%$, enquanto no Assentamento Picada, ela foi de 21,87\%. Para a Amostra Total, o Índice Ambiental contribuiu com $29,99 \%$ do Índice de Sustentabilidade (IS). Isto ocorre porque os assentados do assentamento Macapá se preocupam com a degradação do solo e utilizam esterco animal para o plantio, diferentemente dos assentados do Assentamento Picada que não se preocupam com a degradação e não utilizam esterco.

Recomenda-se às autoridades programar atividades que venham a alavancar a qualidade de vida nos assentamentos, principalmente aquelas atividades relacionadas, neste caso, ao sistema de condições sanitárias e higiene nas três comunidades, principalmente no assentamento Picada. Outro ponto essencial será fomentar as atividades econômicas existentes e lucrativas para o assentamento, já que somente no assentamento Macapá existe uma segunda atividade econômica além da agricultura de subsistência, que é a ovinocaprinocultura. Incentivar os assentados ao cuidado com o meio ambiente, capacitação para um melhor uso de terras e programas para financiamento de máquinas para a plantação. 


\section{Referências}

BARRETO, R.C.S. ; KHAN, A.S.; LIMA, P.V.P.S..Sustentabilidade dos Assentamentos no Município de Caucaia-CE. RER, Rio de Janeiro, vol. 43, nº. 02, p. 225-247, abril/junho 2005.

BARRETO, F.D.; GASPAR, D.F; ARAUJO, J.A.. Determinantes da Desigualdade de Renda em Áreas Rurais do Nordeste. Ensaio Sobre Pobreza $N^{\circ} 18$. Fortaleza: CAEN, 2009.

INSTITUTO DE PESQUISA E ESTRATÉGIA ECONÔMICA DO CEARÁ - IPECE. Perfil Básico Municipal: Sobral. Fortaleza: IPECE, 2010, 16p.

KHAN, A.S.; SILVA, L.M.R.. Capital Social das Comunidades Beneficiadas pelo Programa de Combate à Pobreza Rural - PCPR/ Projeto São José - PSJ - Estado do Ceará. Fortaleza, 2005

SOUZA FILHO, H. M.; SOUSA, M. R.; BUAINAIN, A.M.; SILVEIRA, J.M.; MAGALHÃES, M. M. Programa de reforma agrária Cédula da Terra: medindo a eficiência dos beneficiários. Campinas: UNICAMP, 2003.

TABOSA, F. J. S.; IRFFI, G.; BARRETO, F. A. F. D.; MANSO, C. A.. Taxa de pobreza no estado do Ceará: uma análise no período de 1981 a 2007. V Encontro Economia do Ceará em Debate. Fortaleza: IPECE, 2009. 12p.

TABOSA, F. J. S.; MAYORGA, R. D.; AMARAL FILHO, J. do. Análise de capital social e qualidade de vida da população rural: um estudo de caso no município de Itarema, Estado do Ceará. In: XLIII Congresso da Sociedade Brasileira de Economia e Sociologia Rural, 2005. Brasília-DF: SOBER, 2005. v. 1. p. 1-20. 
Thiago Dias Parente, Francisco José Silva Tabosa,

Fernando Daniel de Oliveira Mayorga \& Silvando Carmo de Oliveira

TABOSA, F. J. S.; MAYORGA, R. D.. O Capital Social no Estado do Ceará: O Caso do Município de Itarema. In: XLIV Congresso da Sociedade Brasileira de Economia e Sociologia Rural, 2006, FortalezaCE. Questões Agrárias, Educação no Campo e Desenvolvimento. Brasília-DF : SOBER, 2006. v. 1. p. 1-20.

TABOSA, F. J. S.; TEIXEIRA, K. H.; SILVA, D. M. F. da; MADALOZZO, C. L.; MAYORGA, M. I. de O.. Desenvolvimento Local e Capital Social: uma Leitura sobre os núcleos e arranjos produtivos do Estado do Ceará. In: XLII Congresso Brasileiro de Economia e Sociologia Rural, 2004. Anais. Brasília: SOBER. v. 1. p. 1-14

UNICAMP. Estudo de Avaliação de Impacto do Programa Cédula da Terra/2001. Campinas-SP,UNICAMP, 2002. 
REVISTA DE ECONOMIA E AGRONEGÓCIO, VOL.9, $N^{\circ} 1$ 